\title{
GEOTHERMAL COOLING FOR DATA CENTERS
}

\author{
Mojtaba Zabihi ${ }^{1,2}$, Ri Li ${ }^{1 *}$, Sai Ram Chanduri ${ }^{1}$, Alireza Hossein Nezhad ${ }^{2}$ \\ ${ }^{1}$ School of Engineering, University of British Columbia, Kelowna, Canada \\ ${ }^{2}$ Department of Mechanical Engineering, University of Sistan and Baluchestan, Zahedan, Iran \\ *sunny.li@ubc.ca
}

\begin{abstract}
The demand for more data centers and consequently power consumption is rapidly growing throughout the world. The most effective way to reduce data center energy consumption is to reduce the power requirement of data center cooling. One concept is geothermal cooling, in which the underground is used as the heat sink. The geothermal cooling system is composed of multiple airwater heat exchangers installed inside the data center building and multiple underground heat rejecters, and the circulation of water between the heat exchangers and underground heat rejecters transfer heat to the ground. The heat rejecter is a tank with thermal storage section buried underground to reject the data center heat to underground soil. This paper investigates the concept of geothermal cooling with focus on the thermal performance of the heat rejecter. Thermal simulation is conducted to simulate the heat rejecter in two operation modes. One mode is under thermal steady state. The results of this mode do not show promising heat transfer performance due to the high thermal resistance. This is also verified by analytical calculation. The other operation mode is based on unsteady state, for which multiple heat rejecters installed with sufficient distance are used in rotation. Each rejecter is used only during its thermal development, and has enough time to almost return to its initial state when other rejecters are being used. It is found that having an effective thermal storage section in the rejecter is important for increasing the heat rejection capacity. Varied heat rejecter designs are tested in the thermal simulation model to evaluate saturation temperature, heat rejection capacity, and thermal impedance.
\end{abstract}

